http://jmscr.igmpublication.org/home/ ISSN (e)-2347-176x ISSN (p) 2455-0450

crossref DOI: https://dx.doi.org/10.18535/jmscr/v8i11.42

Journal Of Medical Science And Clinical Research

\title{
Correlation between interleukin- 6 and Creatine kinase - MB in acute coronary syndrome - A hospital based descriptive study
}

Authors

\section{Dr S.Ranjith Pratap ${ }^{1}$, Dr M.Senthilvelan M.D. ${ }^{2}$, Dr K.Baburaj M.D. ${ }^{3}$}

${ }^{1}$ Post Graduate, Department of General Medicine, Rajah Muthiah Medical College \& Hospital, Annamalai University, Chidambaram, India - 608002

${ }^{2}$ Professor and HOD, Department of General Medicine, Rajah Muthiah Medical College \& Hoapital, Annamalai University, Chidambaram, India - 608002

${ }^{3}$ Professor, Department of General Medicine, Rajah Muthiah Medical College \& Hospital, Annamalai University, Chidambaram, India - 608002

\begin{abstract}
Background: Biomarkers are used in the diagnosis, risk stratification, therapeutic decision making and assessment of clinical outcomes of a patient with ACS. Interleukin -6 (IL-6) is a glycoprotein of about $26 \mathrm{kDa}$ molecular weight. It is responsible for various activities ranging from proinflammatory activities.

Objectives: 1. To find out the mean IL-6 levels and mean CK-MB levels among the patients with myocardial infarction. 2. To find out the difference in mean IL-6 and Mean CK-MB levels between those suffering from STEMI, NSTEMI and Unstable angina. 3. To correlate IL 6 levels with CK -MB levels among patients with myocardial infarction.

Methodology: The present study was a hospital based descriptive study carried out in the department of medicine, Rajah Muthiah Medical College and Hospital, Annamalai University between September 2018 to October 2020 among the patients admitted with chest pain and ECG changes. All the data collected will be entered into Microsoft excel 2019 and master chart was created. The excel sheet was then imported into SPSS (statistical package for social sciences) version 23 for further analysis

Results: The mean value of Creatine kinase MB among the study participants was found to be $66.78 \pm$ $35.698 \mathrm{mg} /$. The mean value of Creatine kinase -MB among those with diagnosis STEMI, NSTEMI and unstable angina was found to be statistically significant for each diagnosis. The mean value of IL-6 among the study participants was found to be $56.67 \pm 22.761 \mathrm{pg} / \mathrm{ml}$. The mean value of IL-6 among those with diagnosis STEMI, NSTEMI and unstable angina was found to be statistically significant for each diagnosis. Both CK MB and IL-6 were strongly positively correlated with $R$ value of 0.8 and $P$ value of < 0.05 .
\end{abstract}

Keywords: Acute coronary syndrome, Cardiac markers, Interleukin - 6, Creatine kinase -MB, STEMI, NSTEMI, Unstable angina.

\section{Introduction}

Present in almost all parts of the world and becoming pandemic in the developing nations, Coronary artery disease (CAD) is one of the major causes of mortality and morbidity in humans ${ }^{1}$. In India too Cardiovascular diseases (CVD) had become the leading cause of mortality, with the turn of the century. In comparison to European 
ancestry Indian were found to be affected a decade earlier, which means among the Indian population CAD occurs in the most productive years of their life $^{2}$.

Atherosclerosis is a 'form of chronic inflammation resulting from interaction between modified lipoproteins, monocyte derived macrophages, $\mathrm{T}$ cells and the normal cellular elements of the arterial wall. This inflammatory process can ultimately lead to the development of complex lesions, or plaques, that protrude into the arterial lumen. Plaque rupture and thrombosis results in superimposed atherothrombosis followed by vascular occlusion' ${ }^{3}$. The above event forms the basic pathology behind various cardiovascular events like myocardial infarction, stroke, limb ischemia and death ${ }^{4}$. CAD is a cardiovascular disorder that occurs mainly due to atherosclerotic occlusion of the coronary arteries ${ }^{1}$.

Researchers around 1950s reported that 'proteins secreted by the necrotic myocytes could be detected in the serum aiding in the diagnosis of myocardial infarction'. From that point of time cardiac biomarkers had grown leaps and bounds and is now playing a central role in the diagnosis of ACS along with ECG. It is not only playing role as a diagnosing tool but also playing a role as a guiding tool aiding in the therapeutic decisionmaking processes of a ACS patient ${ }^{5}$. Biomarkers are used in the diagnosis, risk stratification, therapeutic decision making and assessment of clinical outcomes of a patient with $\mathrm{ACS}^{6}$.

Interleukin -6 (IL-6) is a glycoprotein of about $26 \mathrm{kDa}$ molecular weight. It is responsible for various activities ranging from proinflammatory activities. IL-6 is not only an independent risk factor for unstable CAD but also predictive factor capable of determining mortality risk independent of other established factors like troponin $\mathrm{T}$ and $\mathrm{C}$ reactive protein, creatine kinase $\mathrm{MB}(\mathrm{CK}-\mathrm{MB})^{7}$.

The objectives of the present study were 1 . To find out the mean IL-6 levels and mean CK-MB levels among the patients with myocardial infarction. 2. To find out the difference in mean IL-6 and Mean CK-MB levels between those suffering from STEMI, NSTEMI and Unstable angina. 3. To correlate IL 6 levels with CK -MB levels among patients with myocardial infarction.

\section{Material and Methods}

The present study was a hospital based descriptive study carried out in the department of medicine, Rajah Muthiah Medical College and Hospital, Annamalai University between September 2018 to October 2020 among the patients admitted with chest pain and ECG changes.

\section{Inclusion Criteria}

- Age more than 30 years old and above

- Willing to participate in the study and has given the consent

- Patients admitted with chest pain, ECG changes, abnormal cardiac enzymes.

\section{Exclusion Criteria}

- Rheumatoid arthritis, multiple myeloma, SLE, lymphoma, inflammatory bowel disease, osteomyelitis,

- Infectious disease, immunological disorders.

- Schizophrenia and depression, Alzheimer disease,

- Prostrate cancer,

- Smoker and alcoholic

- Presence or history of liver disease

- Patients with decreased oxygen content, anaemia, pulmonary disease

- Patients with decreased perfusion pressure, hypotension and hypovolemia.

\section{Methodology}

Data for the present study was collected using a pretested sei-structured interview schedule. The schedule consisted of all the variables used for the study in a coherent order. Initial part of the schedule consisted of socio-demographic data of the study participants like age and sex. Following which the probable symptoms of acute coronary syndrome and its differential diagnosis were included. Past history regarding whether any treatment have been taken in the past for similar episodes of ACS and presence of comorbid conditions were asked. The above is followed by 
treatment history. Personal history of the study participants were recorded, including smoking, alcohol, betel nut / tobacco usage, diet, sleeping, bowel and bladder habits. Following the record of all the above histories into the interview schedule, all the participants were examined clinically. A detailed general examination of the participants was done following which systemic examination were performed. During the above process, vitals like pulse rate, blood pressure, $\mathrm{spO} 2$ and temperature were also recorded. Following which a 6-lead electrocardiogram will be performed on all the study participants. Venous blood will be taken and will be sent to the basic bio-chemical investigations, renal function test, urine microalbumin, cardiac enzymes and interleukin 6. Based up on the ECG, the study participants will be classified into STEMI, NSTEMI and Unstable angina. The interleukin levels and all other biochemical values for each study participant will be recorded.

\section{Statistical Analysis}

All the data collected will be entered into Microsoft excel 2019 and master chart was created. The excel sheet was then imported into SPSS (statistical package for social sciences) version 23 for further analysis. Quantitative variables were expressed using mean and standard deviation while qualitative variables were expressed using proportions and percentages. To compare the means, Analysis of variance (ANOVA) was employed. To compare distribution of variable between the groups, Chi square test was employed.

\section{Results}

The mean age among the study participants was found to be $56.19 \pm 11.90$ years. The mean age among those with diagnosis STEMI, NSTEMI and unstable angina was $54.49 \pm 12.13$ years, $56.54 \pm$ 11.58 years and $57.16 \pm 12.18$ years, respectively. All the three were similar with respect to age. $56 \%$ of the study participants were males and $44 \%$ were females. Among the males, $35.7 \%$ had NSTEMI, 31\% had STEMI and 33.3\% had unstable angina. Among the females, $43.9 \%$ had NSTEMI, $33.3 \%$ had unstable angina and $22.7 \%$ had STEMI (Table 1).

The mean value of Creatine kinase MB among the study participants was found to be $66.78 \pm$ $35.698 \mathrm{mg} / \mathrm{l}$. The mean value of Creatine kinase MB among those with diagnosis STEMI, NSTEMI and unstable angina was 92.39 \pm $22.40 \mathrm{mg} / 1, \quad 86.85 \pm 17.8 \mathrm{mg} / \mathrm{l}$ and $22.10 \pm$ $4.06 \mathrm{mg} / \mathrm{l}$, respectively. The mean was found to be statistically significant for each diagnosis (fig 1).The mean value of IL-6 among the study participants was found to be $56.67 \pm 22.761 \mathrm{pg} / \mathrm{ml}$. The mean value of IL-6 among those with diagnosis STEMI, NSTEMI and unstable angina was $71.20 \pm 7.41 \mathrm{pg} / \mathrm{ml}, 72.02 \pm 6.69 \mathrm{pg} / \mathrm{ml}$ and $26.64 \pm 9.82 \mathrm{pg} / \mathrm{ml}$, respectively. The mean was found to be statistically significant for each diagnosis (Fig 2). Both CK MB and IL-6 were strongly positively correlated with $\mathrm{R}$ value of 0.8 and $\mathrm{P}$ value of $<0.05$ (Fig 3).

Table 1: Distribution according to the sociodemographic characteristics

\begin{tabular}{|l|l|c|c|c|c|}
\hline \multicolumn{2}{|l|}{ Variables } & $\begin{array}{c}\text { STEMI } \\
(\mathbf{n = 4 1})\end{array}$ & $\begin{array}{c}\text { NSTEMI } \\
(\mathbf{n = 5 9 )}\end{array}$ & $\begin{array}{c}\text { Unstable angina } \\
(\mathbf{n = 5 0})\end{array}$ & $\begin{array}{c}\text { Total } \\
(\mathbf{n = 1 5 0})\end{array}$ \\
\hline \multirow{2}{*}{ Age } & $54.49(12.13)$ & $56.54(11.58)$ & $57.16(12.18)$ & $56.19(11.90)$ \\
\hline \multirow{2}{*}{ Sex } & Male & $26(31.0)$ & $30(35.7)$ & $28(33.3)$ & $84(56.0)$ \\
\cline { 2 - 6 } & Female & $15(22.7)$ & $29(43.9)$ & $22(33.3)$ & $66(44.0)$ \\
\hline
\end{tabular}




\section{JMSCR Vol||08||Issue||11||Page 242-247||November}

Fig 1: Bar chart showing the mean CK-MB levels between the diagnosis

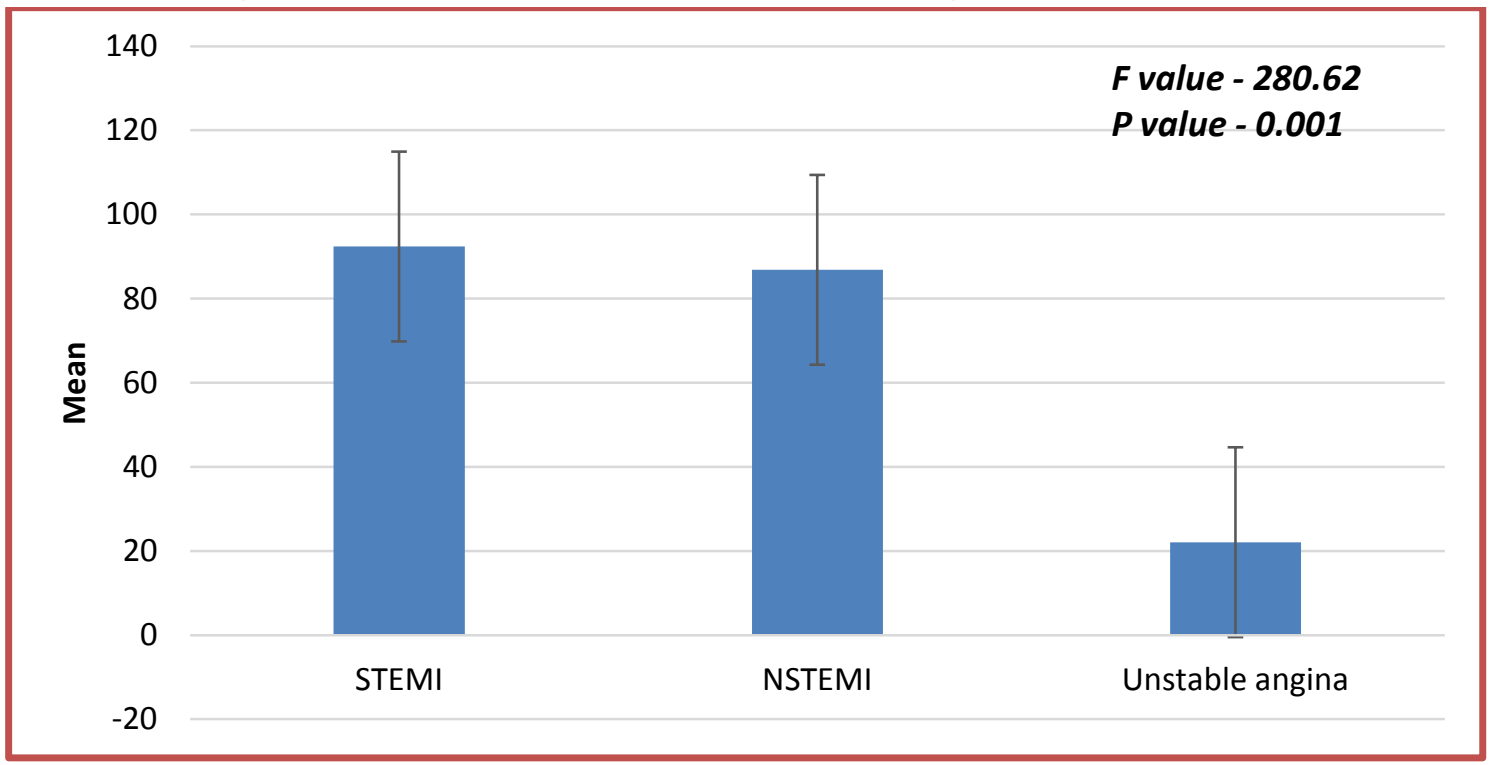

Fig 2: Bar chart showing the mean IL-6 levels between the diagnosis

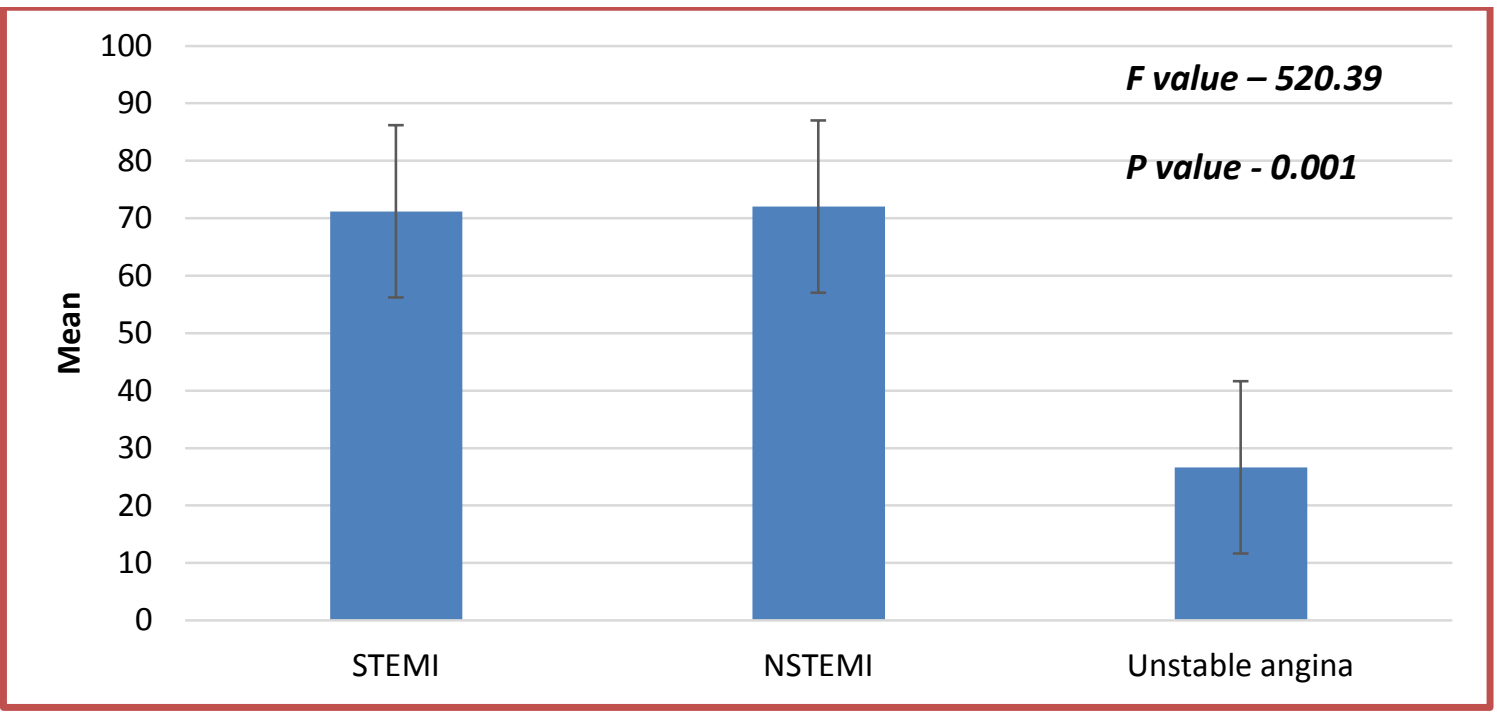

Fig 3: Correlation between CK-MB and IL-6.

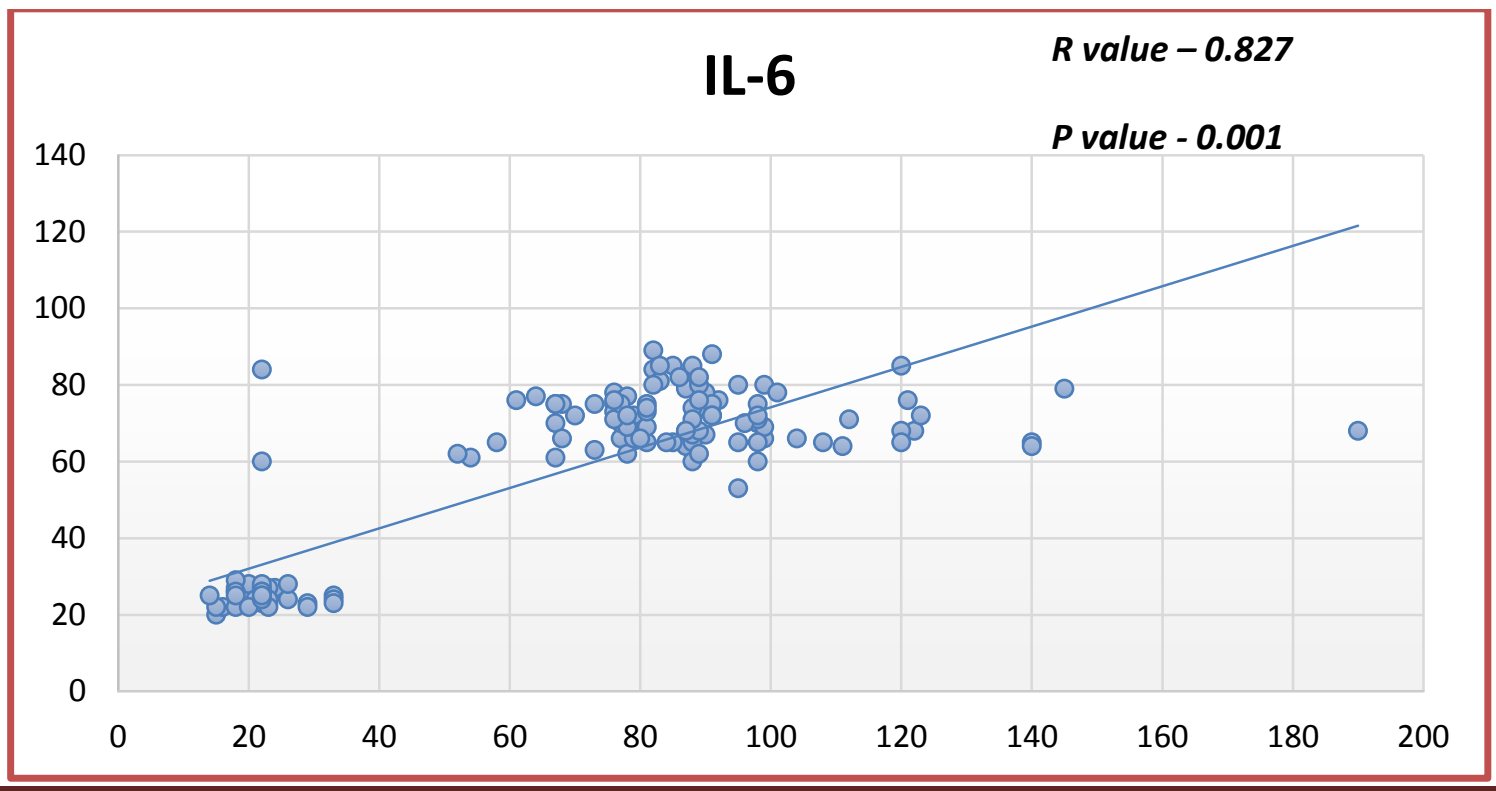




\section{Discussion}

This was a descriptive cross-sectional study conducted in department of medicine, Rajah Muthiah medical college, Annamalai university with an objective of determining level of interleukin -6 values in acute coronary syndrome. Patients attending to the internal medicine department with complaints of chest pain along with ECG changes formed the study participants of the study. 150 such study participants were included into the study and their interleukin 6 levels and CK-MB levels were determined.

The mean value of Creatine kinase MB among the study participants was found to be $66.78 \pm$ $35.698 \mathrm{mg} / \mathrm{l}$. The mean value of Creatine kinase MB among those with diagnosis STEMI, NSTEMI and unstable angina was $92.39 \pm 22.40$ $\mathrm{mg} / \mathrm{l}, 86.85 \pm 17.8 \mathrm{mg} / \mathrm{l}$ and $22.10 \pm 4.06 \mathrm{mg} / \mathrm{l}$, respectively. The mean was found to be statistically significant for each diagnosis. Similar pattern was found in troponin too, all the participants with diagnosis of STEMI and NSTEMI were positive for troponin and the rest were negative. Gibbler et al reported that CK-MB is a valid tool for early diagnosing of AMI and providing appropriate management ${ }^{8}$. Lin JC et al in his study reported that troponin is more specific a cardiac marker than CK-MB ${ }^{9}$.

The mean value of IL-6 among the study participants was found to be $56.67 \pm 22.761 \mathrm{pg} / \mathrm{ml}$. The mean value of IL-6 among those with diagnosis STEMI, NSTEMI and unstable angina was $71.20 \pm 7.41 \mathrm{pg} / \mathrm{ml}, 72.02 \pm 6.69 \mathrm{pg} / \mathrm{ml}$ and $26.64 \pm 9.82 \mathrm{pg} / \mathrm{ml}$, respectively. The mean was found to be statistically significant for each diagnosis. The mean IL-6 values for those diagnosed with either STEMI or NSTEMI were found to be similar while those with unstable angina had a lower IL-6 value than when compared with those suffering from STEMI or NSTEMI.

Ikeda et al reported that plasma concentrations of IL-6 reflect the intensity of occult plaque inflammation. It can aid in determining the vulnerability to restenosis after $\mathrm{PCI}^{10}$. Alwiidrus et al reported that the IL-6 levels among those with Acute coronary syndrome was higher than those with CHD. He further added that an interleukin-6 level of $4.43 \mathrm{pg} / \mathrm{mL}$ could differentiate ACS from non-ACS with sensitivity and specificity of $89.95 \%$ and $77.42 \%$, respectively ${ }^{11}$. Li $\mathrm{H}$ et al in their study reported that measurement of blood interleukin -6 levels might have the potential to improve risk stratification of ACS. The study also reported that increased blood levels of Interleukin -6 was independently associated with higher risk of cardiovascular and all cause mortality in patients with $\mathrm{ACS}^{12}$. IL-6, was positively correlated with CK-MB. With each rise in CK-MB, The magnitude of serum IL-6 also increases. The correlation was found to be strong one.

\section{Conclusion}

IL-6 and CK-MB were positively correlated in myocardial infarction patients indicating IL-6 could also be used as cardiac marker predicting impending cardiac risk.

\section{Reference}

1. Malakar AKr, Choudhury D, Halder B, Paul P, Uddin A, Chakraborty S. A review on coronary artery disease, its risk factors, and therapeutics. J Cell Physiol. 2019 Oct;234(10):16812-23.

2. Prabhakaran D, Jeemon P, Roy A. Cardiovascular Diseases in India. :16.

3. Glass C, Witztum J. Atherosclerosis: The Road Ahead. Cell. 2001 Feb 23;104:50316.

4. Bauersachs R, Zeymer U, Brière J-B, Marre C, Bowrin K, Huelsebeck M. Burden of Coronary Artery Disease and Peripheral Artery Disease: A Literature Review. Cardiovasc Ther. 2019 Nov 26;2019:1-9.

5. Morrow DA, Braunwald E. Future of Biomarkers in Acute Coronary Syndromes: Moving Toward a 
Multimarker Strategy. Circulation. 2003 Jul 22;108(3):250-2.

6. Moe KT, Wong P. Current Trends in Diagnostic Biomarkers of Acute Coronary Syndrome. 2010;39(3):7.

7. Barton BE. The biological effects of interleukin 6. Med Res Rev. 1996;16(1):87-109.

8. Gibler WB, Lewis LM, Erb RE, Makens PK, Kaplan BC, Vaughn RH, et al. Early detection of acute myocardial infarction in patients presenting with chest pain and nondiagnostic ECGs: Serial CK-MB sampling in the emergency department. Ann Emerg Med. 1990 Dec;19(12):135966.

9. Lin JC, Apple FS, Murakami MM, Luepker RV. Rates of Positive Cardiac Troponin I and Creatine Kinase MB Mass among Patients Hospitalized for Suspected Acute Coronary Syndromes. Clin Chem. 2004 Feb 1;50(2):333-8.

10. Ikeda U, Ito T, Shimada K. Interleukin-6 and acute coronary syndrome. Clin Cardiol. 2001 Nov;24(11):701-4.

11. Alwi I, Santoso T, Suyono S, Sutrisna B, Kresno SB. The Cut-off Point of Interleukin-6 Level in Acute Coronary Syndrome. 2007;39(4):6.

12. Lindmark E, Diderholm E, Wallentin L, Siegbahn A. Relationship Between Interleukin 6 and Mortality in Patients With Unstable Coronary Artery Disease: Effects of an Early Invasive or Noninvasive Strategy. JAMA. 2001 Nov 7;286(17):2107. 